\title{
Proposal for Creating a Pocket of Innovation and Adaptability Within a Bureaucratic Enterprise
}

T. T. Nichols

C. B. Millet

June 2001

Idaho National Engineering and Environmental Laboratory Bechtel BWXT Idaho, LLC 


\title{
Proposal for Creating a Pocket of Innovation and Adaptability Within a Bureaucratic Enterprise
}

\author{
Todd T. Nichols \\ Clark B. Millet
}

June 2001

Idaho National Engineering and Environmental Laboratory High Level Waste Program Idaho Falls, Idaho 83415

Prepared for the

U.S. Department of Energy Assistant Secretary for Environmental Management

Under DOE Idaho Operations Office

Contract DE-AC07-99ID13727 


\begin{abstract}
A conceptual framework is developed that is based on a behavioral model for organizations that rely upon innovation and adaptability for their survival in the market place. The model supports the assertion that change efforts aimed at performance improvement need a systems approach because contributions to an organization's performance cross functional lines and are systemic in nature. The model implies four conclusions for a unit trying to effectuate change within a greater bureaucracy. First, the desired behaviors are currently neither evaluated nor rewarded enough by either the enterprise or the local unit. Second, the model has to be applied to the local unit, treating the unit as a distinct enterprise itself. Third, a misalignment between the unit's new form and that of the rest of the enterprise will invariably be created. Fourth, this misalignment has to be minimized enough by the local unit to avoid the larger enterprise from responding negatively to the change effort. The model results in a change approach that constrains localized behavior modification by the need to remain aligned with the overall structure of the complete enterprise. The conceptual framework is used to develop a proposal for effectuating behavioral change within the High-Level Waste (HLW) Program at the Idaho National Engineering and Environmental Laboratory (INEEL). A "strawman" involving a set of critical systems, performance and evaluation measures, and tactics is presented as a starting point for further discussion and development within the Program organization.
\end{abstract}




\section{SUMMARY}

A conceptual framework is presented that is based on a behavioral model for organizations that rely upon innovation and adaptability for their survival in the market place. The ideas of several researchers and practitioners were fused together to create the behavioral model. It takes a systems view of organizations and is based on the following premises:

- The "marketing concept" - organizational success is achieved by meeting customer's needs

- Meeting customer needs requires that management maintain a clear focus on improving performance

- Management has to do three things to have continual performance improvement:

1) Maintain consistency between its "walk" and "talk"

2) Induce a feeling of strong meaning to the organization's purpose

3) Control systems rather than people

- Behavior modification results from system modification

- Critical systems in an organization usually cross functional lines because they provide strategic capabilities

The model implies four conclusions for a unit trying to effectuate change within a greater bureaucracy. First, the desired behaviors are currently neither evaluated nor rewarded enough by either the enterprise or the local unit. Local unit management has to accept responsibility for its own contributing role to the current absence of the desired behaviors and realize its power to influence the behavior of its own personnel. Second, the model has to be applied to the local unit, treating the unit as a distinct enterprise itself. Third, after successful execution of the change effort a misalignment between the unit's new form and that of the rest of the enterprise will invariably be created because of the antichange nature of the enterprise's bureaucracy. Fourth, this misalignment has to be minimized enough to avoid the larger enterprise from perceiving a challenge and actively resisting.

The model does not offer a quick, simple fix. It supports the assertion that contributions to an organization's performance cross functional lines and are systemic in nature, and therefore, that change efforts aimed at performance improvement need a systems solution. Consequently, the model results in an approach that constrains localized behavior modification by the need to remain aligned with the overall structure of the complete enterprise. This focus on enterprise alignment increases the time and effort required but it also increases the potential effectiveness.

Two pertinent examples regarding implementation are discussed. They suggest that whether a systems approach is implemented formally or informally is not that important. What is important is that the relationships, responsibilities, and roles of employees are changed to force and nourish meaningful cross-functional communications, which facilitates problem solving. The examples also imply that it is best for management to provide only the high-level concepts of the systems approach and delegate filling in the details to subordinates.

The reason for developing the conceptual framework stems from a desire to effectuate behavioral change within the High-Level Waste (HLW) Program at the Idaho National Engineering and Environmental Laboratory (INEEL). Some Program managers feel that the current political and economic environment requires greater innovation and adaptability by the Program than its current capabilities provide. Cost, schedule, and technical baselines are estimated poorly relative to actuals, despite good intentions and attempts by Program personnel to eliminate variances. There is the feeling that the root cause is a failure of Program personnel to communicate effectively across functional lines. This failure prohibits holistic decision making. This results in less effective problem solving and relatively poor planning \& implementation of the cost, schedule, and technical baselines. 
The task of trying to increase the innovation and adaptability of the Program is made more difficult by the fact that the Program is an organizational unit that lies within a much bigger and bureaucratic enterprise. This bureaucratic web flows down from the country's democratic form of government, a high regard for public safety on the part of American society, and the laboratory's function-based organizational structure. The behaviors that the change managers seek - cross-functional communication, integration, empowerment, long-term and holistic thinking, calculated risk taking, and challenging the status quo - are not inherently fostered by the parent bureaucratic enterprise.

The HLW Program at INEEL has two main functional organizations: Operations and the Office. Operations involves Manufacturing, Maintenance, and low-level Process Engineering. The Office consists of Technology Development, Strategic Planning, Projects, and higher-level Process Engineering. Traditionally, the main focus of the Office is planning, while the main focus of Operations is implementation. Office management perceives the same lack of integration and communication between the functional sections within the Office itself as it perceives between the Office and Operations.

The conceptual framework is applied specifically to the INEEL HLW Program Office. Office management feels strongly that DOE values the capability to implement a path forward for the treatment of waste within an optimum balance between schedule and cost that are accurately estimated beforehand. A set of critical systems, performance and evaluation measures, and tactics are proposed to help foster within the Office the desired behaviors required for innovation, helping to create the valued capability within the Program. The strawman presented is deliberately incomplete because its purpose is explanatory. It is meant to be a starting point for further discussion and development by the Program. 


\section{CONTENTS}

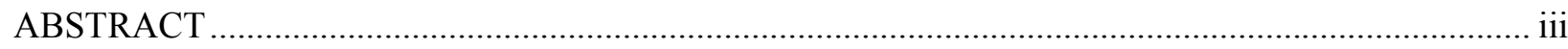

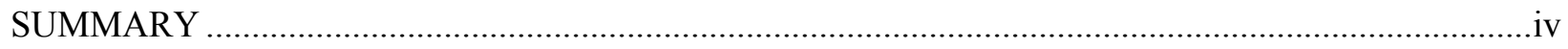

INTRODUCTION

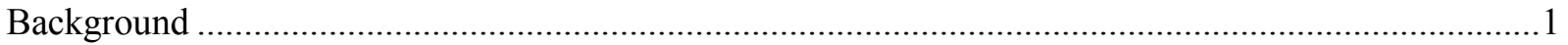

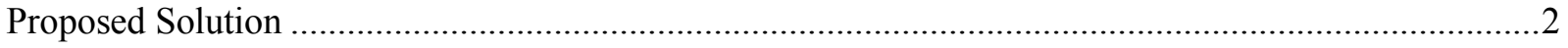

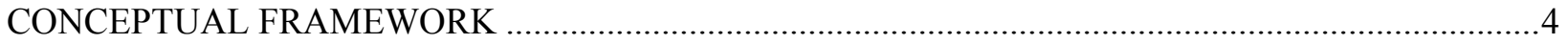

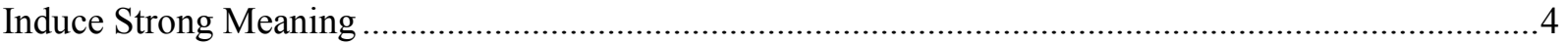

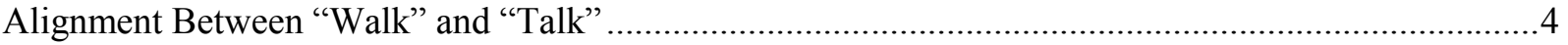

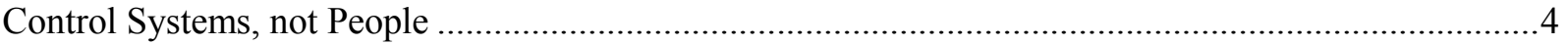

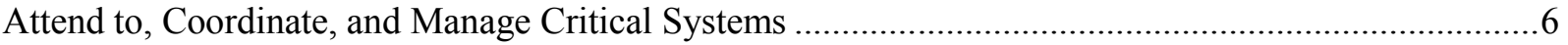

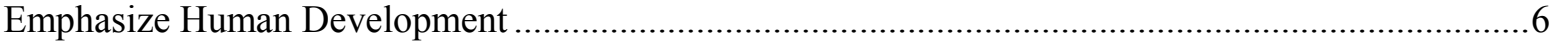

Tie Behavior, Measures, Objectives, and Customer Needs Together .......................................... 6

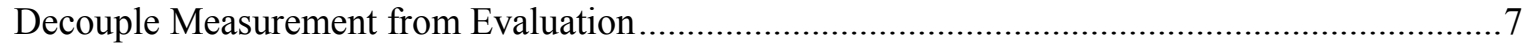

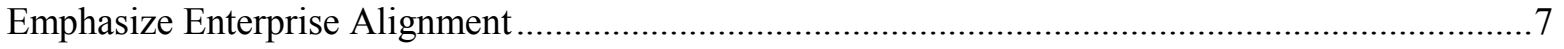

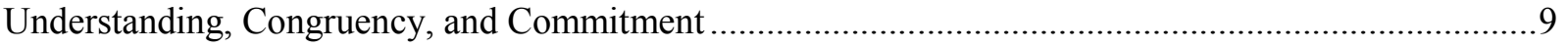

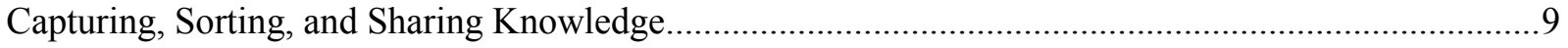

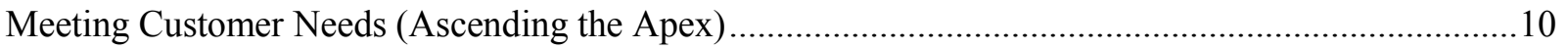

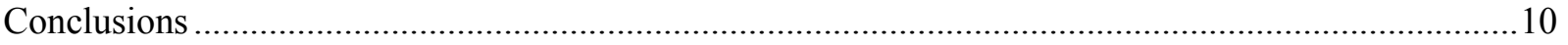

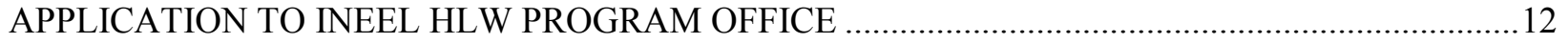

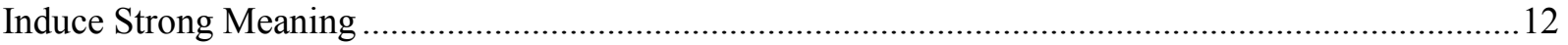

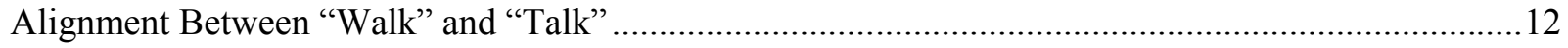

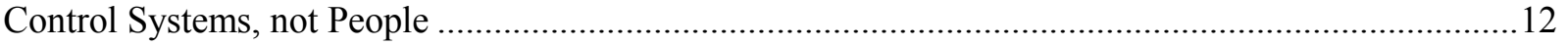

Attend to, Coordinate, and Manage Critical Systems ........................................................................ 16

Emphasize Human Development ...................................................................................... 16

Tie Behavior, Measures, Objectives, and Customer Needs Together ........................................16

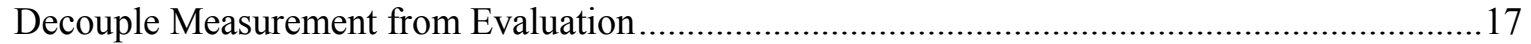

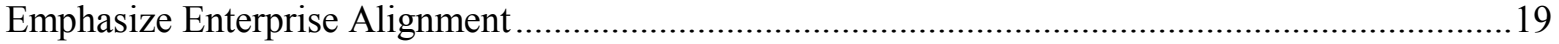

Understanding, Congruency, and Commitment ............................................................................... 19

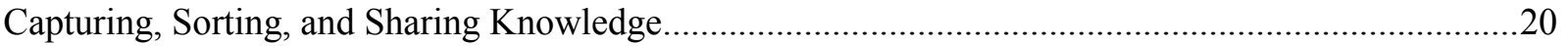

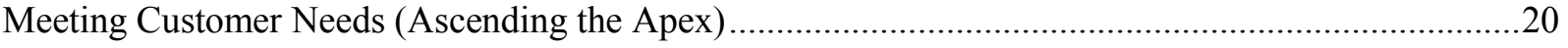

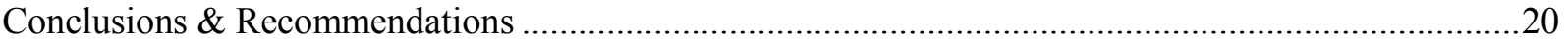

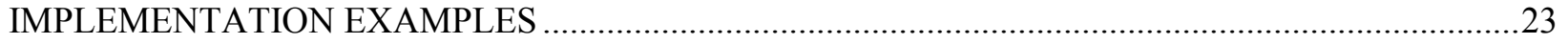

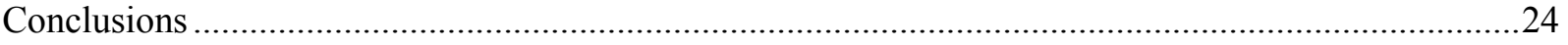

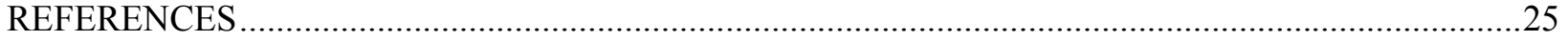




\section{FIGURES}

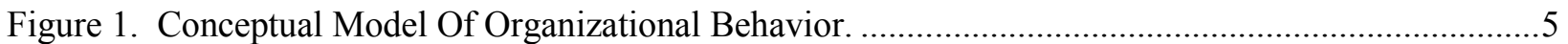

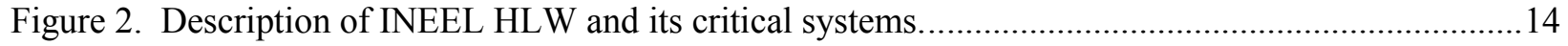

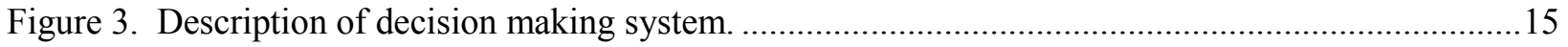

Figure 4. Tying Customer Needs To Employee Behavior. ................................................................ 18 


\title{
Proposal for Creating a Pocket of Innovation \& Adaptability Within a Bureaucratic Enterprise
}

\author{
INTRODUCTION
}

\begin{abstract}
Management of the INEEL HLW Program Office feels that the current political and economic environment requires greater innovation and adaptability by the Program than its current capabilities provide. Cost, schedule, and technical baselines are estimated poorly relative to actuals, despite good intentions and attempts by Program personnel to eliminate variances. Planning and implementation of the baselines have to improve because the political and economic environments are forcing the federal customer to simultaneously require greater work scope and smaller budgets. If the Program doesn't increase its capacity to innovate and continuously adapt to changing customer requirements, it risks having the customer choose a more nimble site or contractor to perform the work scope.
\end{abstract}

Office management feels that the root cause is a failure of Program personnel to communicate effectively both internally and externally. This failure prohibits decisions to be made in a manner as systematic, integrated, and comprehensive as desired. This results in less effective problem solving and relatively poor planning \& implementation of the cost, schedule, and technical baselines.

\section{Background}

Office management understands that its judgement and perception are relative to a goal. Management's dissatisfaction lies not in a comparison with past performance but rather with the difference between its perception of current reality and its perception of what is required in the future. DOE is nearing the end of a multi-year endeavor to select technologies for final treatment of liquid and solid HLW at INEEL. HLW has both radioactive and hazardous constituents. A Record of Decision (ROD) for treatment is expected within the

year. The United States Department of Energy (DOE) will expect the HLW Program to plan and implement the path forward outlined in the ROD within an optimum balance between schedule and cost that are accurately estimated up front. If the HLW Program can not perform as expected, DOE will find another organization that can.

Office management is frustrated that the Program's competent and conscientious employees appear to perform less effectively as a group than they can as individuals. Office management feels that improving the communication and integration of Program personnel is key to producing the desired superior performance.

The Program has two main functional organizations: Operations and the Office. Operations involves Manufacturing, Maintenance, and low-level Process Engineering. The Office consists of Technology Development, Strategic Planning, Projects, and higher-level Process Engineering. Traditionally, the main focus of the Office is planning, while the main focus of Operations is implementation. Office management perceives the same lack of integration and communication between the functional sections within the Office as it perceives between the Office and Operations.

The task of trying to increase the innovation and adaptability of the Program is made more difficult by the fact that the Program is an organizational unit that lies within a much bigger and bureaucratic enterprise. A federal laboratory such as INEEL has multiple organizational players, each with distinct characteristics. The 
customer and overseer, DOE, inherits several characteristics from its parent federal governance structure: voluminous procedures, top-down management, a funding-based organizational structure, extended schedules for capital projects because of drawn out congressional funding cycles, and a political organization and culture overlay characterized by short-term policy commitments dictated by the election process.

The fact that the HLW Program manages nuclear facilities brings additional controls and oversight that constrain individual innovation even further - most people prefer standardized procedures at nuclear facilities rather than empowered operators solving problems "by the seat of their pants." Concern for employee and public safety at a nuclear facility inherently diminish the desired level of employee empowerment.

The site itself has traditionally had an organizational structure based on function, which tends to create "silos" and to prevent cross-functional coordination. ${ }^{7}$ The federal governance, nuclear controls, and the site organizational structure in aggregate produce a culture and work environment that does not inherently foster innovation and adaptability. The INEEL HLW System is essentially a subpart of a top-down, short-sighted, slow acting, category- and function-based organizational hierarchy that attempts to mitigate high political and health risks by limiting the degrees of freedom of employees. Cross-functional communication, integration, empowerment, long-term and holistic thinking, calculated risk taking, and challenging the status quo are not inherently fostered by such an enterprise.

The caricature given above of the larger enterprise may appear to be negative, but no judgement is intended. Much of the bureaucratic web that cascades down to a federal nuclear laboratory is a natural result of having a democratic form of government and American society's high regard for safety. Some seeminglyinefficient governance characteristics of a federal nuclear laboratory may simply be some of the required costs for the benefits of political freedom and public safety.

This report doesn't focus on the larger enterprise - the flow down from the federal governance, public safety, and site organization - because that is outside the sphere of direct influence of Office management. It is briefly described because it is an environmental reality that Office management has to deal with when attempting to solve its problem. Instead, the change proposal focuses on what can be done within the Office and Program organizations to solve the problem and thereby improve performance.

\section{Proposed Solution}

This report presents a proposal from two systems engineers in the Strategic Planning section of the Office for changes to create a Program that will have synergy, a Program that will be greater than the sum of its parts, and a Program whose performance will be superior to what its good employees could do individually. The proposal was requested by Office management.

There are two basic alternative solutions:

- The traditional functional view of organizations - results in a task-oriented recommendation with a management-by-objective (MBO) type of monitoring mechanism. It assumes that each functional organization has total control over its performance. It would be simple to implement because it would include narrowly-defined, easy-to-track performance standards.

- A systems approach - accounts for the interdependencies between organizational units and assumes that critical, value-adding activities are of a cross-functional nature that require goal congruency and alignment across functional units. Dealing with this complexity requires more skill and attention 
from managers because it demands a holistic view and requires cross-functional performance standards.

A solution based in the traditional view would not produce the desired change in employee behavior towards more cross-functional problem solving because of its functional myopia and ignorance-of-the-means associated with MBO. Consequently, an effective systems solution based in simple concepts but a more complex implementation is recommended.

The proposal has a strong emphasis on improving the performance of the Office because that is all Office management has direct influence over and because the Office is plagued by the same problems perceived for the Program as a whole. The majority of Office personnel are scientists and engineers and perform technical functions. The products coming out of the Office - cost, schedule, and technical baselines - need to be innovative and adaptable because of changing technological, political, and economic environments. Because nuclear facilities are involved, Operations personnel are also highly trained and have to balance the cost, schedule, and technical issues on a day-to-day basis.

The proposal has two parts: a conceptual framework and an application strawman. A systems-based conceptual framework is presented of a behavioral model for organizations that rely upon innovation and adaptability for their survival in the market place. The model is created from the work and insights of various researchers. The model is then applied specifically to the INEEL HLW Program Office. The proposal is followed by a few pertinent examples regarding implementation of systems-based solutions to organizational problems are discussed. 


\section{CONCEPTUAL FRAMEWORK}

A conceptual model of behavior within an organization dependent upon innovation and adaptability for its success is proposed and shown in Figure 1. A business is created to satisfy certain needs of targeted customers, so the task of leadership is to improve the organization's performance to increase value to the customers. This explicit tie between business performance and customer needs is the foundation of the "marketing concept" (Kotler 1997) and a basis of the model. Leaders can continually improve organizational performance by concentrating on three activities: 1) induce within members a feeling of strong meaning to the work and cause of the organization, 2) religiously "walk the talk," and 3) control systems rather than people. The proper focus on these three activities will result in knowledge being properly utilized, which allows high levels of innovation and adaptability to be achieved. This focus ultimately leads to organizational objectives being achieved and customer needs being met.

\section{Induce Strong Meaning}

Pascale, Millemann, and Gioja (1997) claim that leaders attaching meaning and urgency to the organization's mission and clearly communicating the connection helps to generate strong intrinsic satisfaction in the members. Although this logical principle may appear to be nothing more than common sense, it is many times neglected by management.

\section{Alignment Between "Walk" and "Talk"}

Strebel (1996) asserts that alignment between management's words and behavior is key to creating member commitment. Leaders need to be consistent role models for any value they wish the members to emulate. Kornacki and Silversin (1998) concur with this principle, feeling that inconsistency and slippage sends the message to staff that the leaders are not serious about the adoption of the behavior. Failure of leadership to "walk the talk" is a main reason for failure of change programs in organizations. Because of the importance of leadership's example and the fact that people at the top are in the best position to change organizational forces and systems, it is claimed by Bounds, Reeve, and Gilbert (1991) that the top priority when attempting to change behavior in the members is to change manager behavior.

\section{Control Systems, not People}

The third key activity - control systems rather than people - is based upon the holistic assumption that work gets done in an organization through systems that cut horizontally across the entire organization. This can be a valid assumption for an enterprise when one or more of the following three conditions describe its products or services: 1) they are complex, require customization, and are not available off-the-shelf; 2) they require special materials, training, disposal, etc; or 3) they can't be produced entirely within one discipline or function (Kirby 1991; Anthony and Govindarajan 1998). Managing liquid and solid radioactive and hazardous waste requires customized rather than standard solutions, involves specialized materials and training, and depends upon several scientific and engineering disciplines. Consequently, the INEEL HLW Program is an organization that requires systems that cut across functional units to provide its technology-based services. 


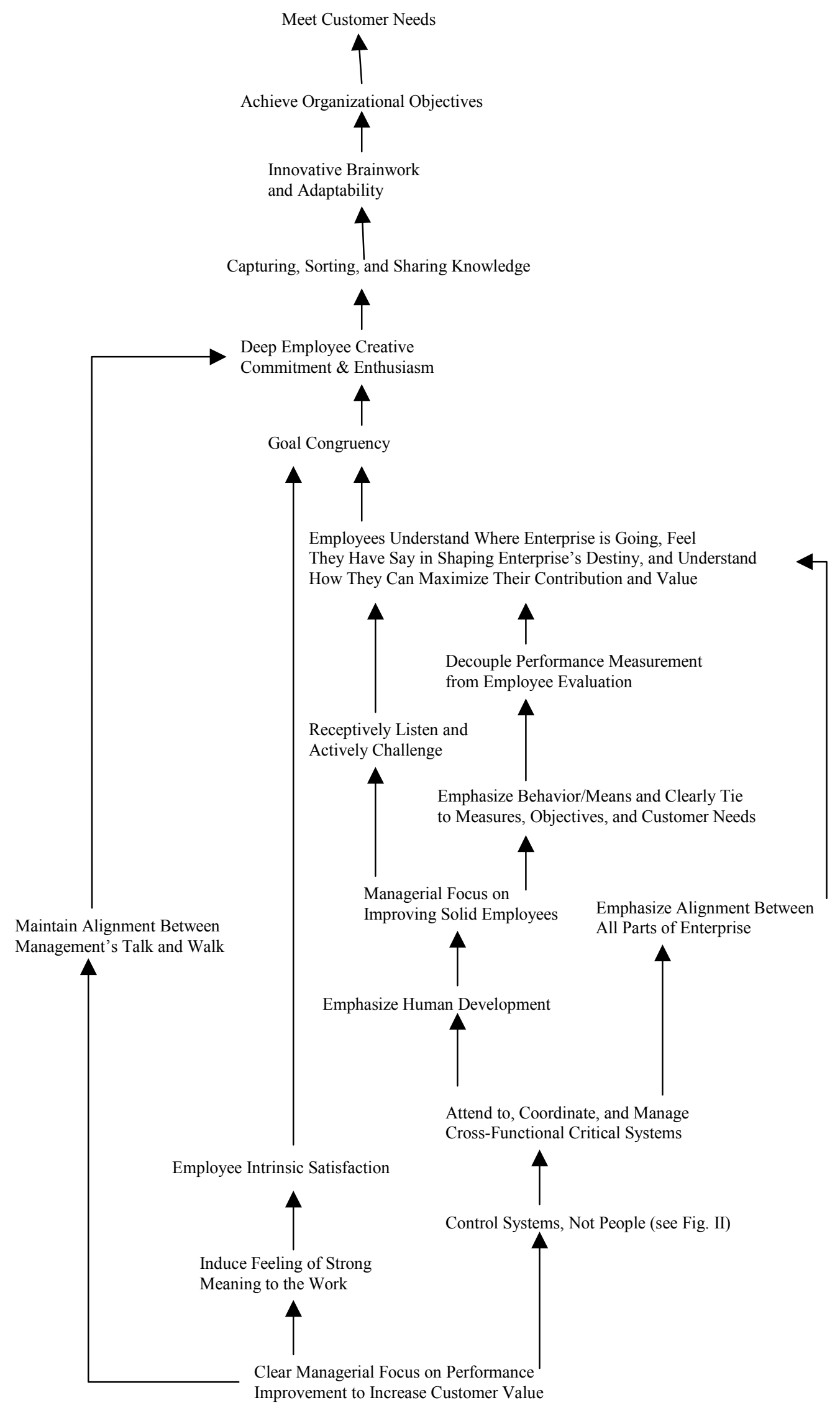

Figure 1. Conceptual Model Of Organizational Behavior. 
This systems approach is different from the traditional, reductionist view of an organization as merely the sum of several different departments or functions that have individual responsibilities for the success of the organization. Under the traditional paradigm, interaction between functional units is often limited to written reports and infrequent meetings where the main objective is to merely pass on cost and schedule variances. There is little cross-functional interfacing oriented toward multi-department problem solving with the objective of increasing customer value (Kirby 1991).

\section{Attend to, Coordinate, and Manage Critical Systems}

The primary influence of employee behavior within INEEL HLW System, as with any human-based system, stems from the system's structure (training, equipment, information, work environment, culture, performance measures, punishments/rewards, materials, organizational demands, procedures and methods, etc.). Organizational leaders - as sculptures of the system - have to accept major responsibility for organizational performance and overall employee behavior. Bounds, Reeve, and Gilbert (1991) assert that management needs to focus on controlling the system rather than people because behavior modification results from system modification.

Ownership has to be assigned for critical systems in order to adequately control them. Otherwise, improvement of the individual critical systems and the organizational whole will be constrained. The manager of each critical system must be personally responsible for inputs, outputs, processes, procedures, and policies pertaining to the system that transcend departmental boundaries and provide customer value. Otherwise, Bounds, Reeve, and Gilbert (1991) claim that leaving these critical systems unattended, uncoordinated, and unmanaged will result in a loosely connected, hodgepodge system of various functional activities and processes that produce value-deficient outcomes (i.e., results in the traditional, reductionist model of organizations).

Kirby (1991) recommends the following criteria for the owner of a critical system: 1) holds a senior management position because critical systems cross functional boundaries: 2) holds a position that has the most to gain from system improvement; 3) manages the largest number of people working in the system; 4) understands the entire system; 5) has an overall perspective of the effect of the environment on the system and the effect of system performance on the entire organization; and 6) has the personal ability to influence decisions and people outside of his/her line management responsibilities.

Referring to Figure 1 again, it can be seen that the conceptual model focuses on two tactics to manage the critical systems: emphasizing human development and enterprise alignment. In this discussion, the terms measurement and evaluation are distinct and separate. Measurement is a fact, and evaluation is a judgment.

\section{Emphasize Human Development}

It is important for leadership to stress human development rather than evaluation. Performance measurement should be used to develop employees to be better at controlling and improving the critical systems. After all, managing the critical systems, not employees, is the higher aim. Improving the solid employees is more important than controlling the degrees of freedom of the worst employees. Employee improvement is hard work. It requires leaders that both receptively listen and actively challenge as they teach desired behaviors (Bounds, Reeve, and Gilbert 1991; Saunier and Mavis 1998; Hawkins 1997).

\section{Tie Behavior, Measures, Objectives, and Customer Needs Together}

Measurements of system performance should regard both employee behavior and organizational results, and they need to be determined for all levels. Each critical system has transfunctional and broad performance 
measures that are strategically linked to capabilities that produce value for the customer. These, in turn, flow down to subsystems which have their own lower-level, interrelated objectives and measures. This cascading structure continues down to the lowest system level. In this way, causal factors like behaviors (means) are managed to improve criteria (ends). The work of several researchers (Bounds, Reeve, and Gilbert 1991; Anthony and Govindarajan 1998) suggests that clear causal links must be made between each level and that employees need to understand these linkages to know the purpose of their activities.

Consequently, the value added for the customer is linked to a desired employee behavior via critical systems and performance measures. It is important to realize that the aim is to have employee behavior that produces a strategic capability that satisfies a customer need; the measures and critical systems are created to keep the organization focused on continually matching needs to behavior.

If the behavior change occurs and measures improve but customer satisfaction appears to be unchanged, there could be two explanations: 1) the targeted behavior is not contributing to the valued capability as much as management thought it would, or 2) the capability is being created but the customer doesn't value it as much as management expected.

\section{Decouple Measurement from Evaluation}

The purpose of performance measurements is to monitor and modify the means to improve the ends: one can't do that if the means become the ends. Consequently, performance measurement must be decoupled from employee performance evaluation. Otherwise measures become ends in themselves - employees optimize the measures rather than study variation and its root causes. The focus becomes diverted to the measures rather than employee behavior. A focus on measures rather than behavior invariably results in employees "gaming" the system and exhibiting behavior that is detrimental to the organization's overall objectives.

This recommendation is a 180 degree turn from the management-by-objective (MBO) mantra of the 1980s. Bounds, Reeve, and Gilbert (1991) advocate that management drop MBO and appraise employees on their efforts to study variation and contribute to the means (behavior). This requires subjective evaluations of individual's performance/contribution and appeals less to the carrot and stick approach and more to one's need for achievement, intrinsic motivation, job enrichment, superordinate attitudes, information feedback, selfappraisal, and social recognition.

Because of the subjective nature of the broadly-defined criteria, focusing on effort and behavior requires that the manager be intimately involved with, and knowledgeable of, the efforts of his staff. It requires much more effort and managerial skill than does the MBO approach.

When coupled with bottoms-up innovation, this evaluative focus on effort and behavior is referred to by some as "interactive control." Simons (1995) feels that this type of control system is especially important under two conditions: 1) when low level employees have more specialized knowledge than managers (as is the case with most professional organizations), or 2) the organization has many members and/or the organization's activities occur over different geographical locations such that the tendency is for managers and employees to not have regular and frequent face-to-face interaction. INEEL HLW, with its cadre of scientists and engineers and close to 100 employees performing various activities at various facilities at the site and at facilities fifty miles away in the city of Idaho Falls, exhibits both conditions, suggesting the need for interactive control.

\section{Emphasize Enterprise Alignment}

Besides emphasizing human development, leadership must assure enterprise alignment if it wants to successfully manage the critical systems (Bounds, Reeve, and Gilbert 1991; Anthony and Govindarajan 1998; Senge 1990). Congruent performance measurement and employee evaluation are critical, but insufficient 
without a complementary rewards system. Managerial control mechanisms - such as organizational performance measures, employee evaluation, and rewards - need to be aligned. Existing managerial control mechanisms, and therefore existing behaviors, will prevail in the long run unless revision of all control mechanisms are given appropriate managerial attention.

Enterprise alignment has two levels - local (or internal) and distant (or external), especially for an organizational unit in the bowels of a bureaucracy that is trying to effectuate change. The unit manager needs to assure that his unit has local alignment, that performance measures, employee evaluations, and reward systems internal to the unit are aligned. The manager needs to apply the organizational behavior model displayed in Fig. 1 directly to his unit. The "customer," for example, may be another down stream organization in the corporation rather than an end-user of the company's products or services.

The fact that the employee behavior desired by the management of the local unit seeking the change is not currently being exhibited to the desired degree is evidence that such behavior is currently neither evaluated nor rewarded enough by either the enterprise or the local unit. It is evidence that neither the enterprise nor the local unit have enough alignment to produce the desired behaviors in their respective organizational spheres. The management of a local unit can produce the desired change within its own unit by aligning all aspects of its organizational sphere with the desired behaviors. Local unit management has direct control, albeit possibly not complete, over the measures, evaluations, rewards, relationships, responsibilities, roles, etc. within its unit.

Distant alignment, or alignment with the rest of the enterprise that is external to the unit, is also important. Bureaucracies by nature reward conformity and resist change. A bureaucracy will attempt to destroy internal forces that appear to challenge its bureaucratic momentum. Consequently, a distant cultural misalignment is especially important for a low-level organizational unit of a bureaucratic enterprise that is trying to execute a localized cultural change. In such an environment, the unit manager will only bring misery upon his subordinates if he preaches that bottoms-up creativity, empowerment, teamwork, and a long-term focus are rewarded by the enterprise at-large. Instead, the manager has to make it clear that he expects and will reward such behavior when appropriate from his staff despite the possibility that other parts of the enterprise may not.

The manager also needs to realize that he may not be rewarded by the enterprise for his change efforts. Indeed the manager may be punished by the enterprise if the local change interferes with the momentum of the enterprise's bureaucratic status quo. Consequently, the manager needs to be careful to not challenge the enterprise's main culture to such a degree that the main culture takes notice, feels threatened, and attempts to kill the emerging subculture.

One possible way to minimize the distant cultural misalignment is to confine the change efforts to the unit and rely solely upon diffusion to spread the subculture in the beginning. Avoid trying to actively spread the change to other parts of the enterprise; let any spread result from other units sensing its benefits and voluntarily embracing it. Slow adoption of the change by other parts of the enterprise may be a draw back of this strategy, but a greater chance of the change surviving is its advantage. Slow progress is better than no progress.

A more active and extensive change effort could be contemplated if and when a critical mass is reached that could effectively handle the resulting increase in resistance from remaining bureaucratic bastions of the enterprise.

The morale of low-level champions of change in bureaucracies may be directly proportional to their ability to perform change in such a way that it provides the desired benefit to their units without directly challenging the bureaucracy. Thus, the manager receives the intrinsic satisfaction of increasing organizational performance and the working conditions of his employees without being punished or actively resisted by the enterprise. Trying to minimize the misalignment between the local and enterprise's cultures is usually a distraction to the manager and increases the time required to execute the change. The morale of energetic 
subordinates in a bureaucratic enterprise may be directly tied to their ability to find and obtain positions in organizational units where patient and politically astute managers have successfully created such "pockets" of calculated risk taking and empowerment.

\section{Understanding, Congruency, and Commitment}

By simultaneously emphasizing human development and alignment with the rest of the enterprise, a leader gives the members of his staff a clear understanding of where the enterprise is going and how they can maximize their contribution and value to help shape its destiny. This understanding couples with intrinsic satisfaction to achieve goal congruency between the employees and the enterprise. Add management "walking the talk," and deep employee creative commitment and enthusiasm are created (Strebel 1996; Pascale, Millemann, and Gioja 1997).

\section{Capturing, Sorting, and Sharing Knowledge}

Knowledge management is serious business for organizations, such as INEEL, in which innovative brainwork translates directly into products and profits (Galagan 1997). Hansen, Nohria and Tierney (1999) make the logical assertion that person-to-person knowledge sharing is crucial and a more effective knowledge capture than person-to-document when employees rely upon tacit knowledge (such as scientific or technological expertise or operational know-how). This is one of the reasons Office management feels that more crossfunctional communications need to occur.

Most companies are groping with the task of capturing, sorting, and sharing their knowledge because they don't encourage employees to talk about what they learn or even admit that they need to learn something. Ignorance and mistakes are not gladly tolerated by most managers, and most employees are rewarded for individual effort and unique skills (Galagan 1997; Vaas 1991). Anthony and Govindarajan (1998) point out that government agencies in a democracy find it even more difficult to adequately share internal information. This is because of the government's counter acting desire to limit the amount of sensitive or controversial information flowing through the formal organization in an attempt to reduce leaks that could lead to unfavorable media stories or security breaches.

In addition to the systemic forces mentioned above, there may be personality traits (i.e., discipline-based subcultures) that tend to impede communications. Bounds, Reeve, and Gilbert (1991) assert that professionals, such as scientists and engineers, find it particularly unnatural to share information with other members of the enterprise: they prefer to work independently rather than in teams, they tend to think unfavorably of administrative tasks, and they tend to ignore the financial implications of their decisions.

However, practicing the principles discussed earlier regarding the emphasis on human development and managing critical systems (such as interactive control, using a behavior-based reward system, and crossfunctional communications) will create a culture where questioning and sharing will be rewarded and nurtured. This will permit deep employee creative commitment and enthusiasm to produce efficient knowledge management. 


\section{Meeting Customer Needs (Ascending the Apex)}

A good knowledge management system will leverage employee creative commitment and enthusiasm to produce innovative brainwork and adaptability, which in turn contributes to organizational objectives being achieved, and ultimately, to the needs of customers being met.

Changing employee behavior, especially by diffusion from a low-level point source like the Program Office rather than a top-down enterprise-wide effort, is a long-term process and requires leadership commitment for the long haul (Morgan 1998). Martin (1997) makes it clear that applying a systems solution requires much: a high level of management attention, energy, and skill; good team communications; creating a working environment accepting of decisions and the status quo being challenged; and the nurturing of a holistic attitude.

Bounds, Reeve, and Gilbert (1991) remind change champions that bottom-line results can suffer a shortterm drop during periods of experimentation or transformation. They claim that improvement in bottom-line results will appear over time if fostered behaviors are truly tied to creating customer value. Improvements typically lag behind managerial or process changes, so persistence and endurance are required

\section{Conclusions}

The ideas of several researchers and practitioners were coordinated and fused together to create a conceptual model of employee behavior in organizations that are dependent upon innovation for success (see Fig. 1). The model takes a systems view of organizations and is based on the following premises:

- The "marketing concept" - organizational success is achieved by meeting customer's needs

- Meeting customer needs requires management to maintain a clear focus on improving performance

- Management has to do three things to have continual performance improvement:

1) Maintain consistency between its "walk" and "talk"

2) Induce a feeling of strong meaning to the organization's work or cause

3) Control systems rather than people

- Behavior modification results from system modification

- Critical systems in an organization are those that provide strategic capabilities, so they usually cross functional lines

- Critical systems are an effective way to increase integration and communication within an enterprise because their use forces meaningful cross-functional communications and enterprise alignment to occur

- Properly attending to, coordinating, and managing the critical systems is key to changing employee behavior on a large scale and thereby continuously add customer value

- Results in an organization that is innovative and can quickly adapt to changing surroundings and conditions

The model implies four conclusions for a unit trying to effectuate change within a greater bureaucracy. First, the desired behaviors are currently neither evaluated nor rewarded enough by either the enterprise or the local unit. Both the enterprise at-large and the local unit lack their own respective alignments. Local unit management has to accept responsibility for its own contributing role to the current absence of the desired behaviors and realize its power to influence the behavior of its own personnel.

Second, the model has to be applied to the organizational unit on a local level, treating the unit as a distinct enterprise itself. Local unit management has direct control, albeit possibly not complete, over internal 
alignment, and it has the responsibility of achieving internal alignment in order to effectuate the desired behavioral changes in its own personnel.

Third, a misalignment between the unit's new form and that of the rest of the enterprise will invariably be created because of the anti-change nature of the greater bureaucracy.

Fourth, this distant cultural misalignment has to be minimized enough to avoid the larger enterprise from perceiving a challenge and actively resisting. One possible way to minimize the misalignment is to confine the change efforts to the unit and rely solely upon diffusion to spread the subculture in the beginning until a critical mass has embraced the change that can support a more active and extensive change effort.

The model doesn't provide a quick, simple fix. The assertion is made that failure to innovate, to adapt, and to communicate across functional lines are systemic problems that need a systems solution. Consequently, the model results in an approach that constrains localized behavior modification by the need to remain aligned with the overall structure of the complete enterprise. This focus on enterprise alignment and congruence increases the time, effort, and managerial skill required but it also increases the potential effectiveness.

The systems-based model is applicable to the INEEL HLW Program Office because of the following conditions: 1) the Office is a low-level unit trying to effectuate change within a larger, bureaucratic enterprise; 2) the INEEL HLW Program is an organization that requires systems that cut across functional units to provide its services that are based on technological innovation (i.e., it requires customized rather than standard solutions, involves specialized materials and training, and depends upon several scientific and engineering disciplines); 3 ) the Office's technical professionals may have a natural resistance to sharing information across functional lines because of their personality type; and 4) government concerns regarding laboratory security and media leaks may tend to discourage information sharing between Program personnel. 


\section{APPLICATION TO INEEL HLW PROGRAM OFFICE}

The conceptual model developed in the previous section is applied specifically to the INEEL HLW Program Office and its situation of desiring to drive change while being a non-autonomous unit in a larger bureaucratic enterprise.

Change is sometimes categorized as developmental, transitional, or transformational (Jick 1993). Developmental change is characterized by "doing more of the same, but better." It is incremental change. Transitional change is when the organization looks new and different after the change, but the leader was able to clearly and concisely foresee the new look. Transformational change is when the new organization looks nothing like the old. The changes have such deep impact that the leader isn't able to foresee the final form. Although the leader can't predict the final look, he is so convinced of the need for the far reaching changes, he proceeds forward anyway.

A change effort limited to the HLW Program isn't transformational in nature because the scope is small and doesn't involve radical reconceptualization of the organization. The desired change isn't developmental because "more of the same" isn't wanted. It is felt that the desired change is transitional because a different and somewhat new form is desired, but the changes wouldn't run so deep that management wouldn't be able to envision the new form. Management could visualize a new state achieved from introducing new processes and systems. Transitional change involves appreciable depth and complexity of implementation and investment of organizational resources.

\section{Induce Strong Meaning}

Office management feels that one of the strengths of the HLW Program is the strong importance that its people place upon the organization's mission. Management feels that Program employees derive intrinsic satisfaction from mitigating a significant safety and environmental concern by safely managing HLW. Office management doesn't see the need for additional management focus on this key activity.

\section{Alignment Between "Walk" and "Talk"}

Office management considers the need for this key activity to be self-evident and accepts its responsibility to "walk the talk."

\section{Control Systems, not People}

Before implementing systems-oriented organizational change, Kirby (1991) feels that the leader needs to: 1) determine what capabilities are and will be valued by customers; 2) identify the member behaviors and critical systems of the organization that produce such capabilities; and 3) gain an understanding of the relationships between these critical systems and their subparts. Office management feels that: 1) the desired capability is to implement the HLW path forward (as determined by the EIS) within an optimum balance between schedule and cost that are accurately estimated beforehand; and 2) the required employee behaviors are cross-functional problem solving and integrated, systematic decision making. Three critical systems to help create the valued capability and facilitate the behaviors are proposed and described below: 
1) Decision Making - assures that decisions and recommendations achieve the path forward safely and cost effectively

a) Knowledge management - assures efficient and effective gathering, storing, retrieval, and distribution of knowledge throughout the organization

b) Coordination control - formal mechanisms to assure that the appropriate information (analyses and stakeholder feedback) and concurrence are obtained and used in the decision making process

i) Risk management - assures the performance of adequate analysis and assessments of financial, technical, reputation, political, and environmental risks of potential decisions

c) Culture

i) Reward system, beliefs, and values

d) Organizational structure

2) Technology Deployment - assures the successful life-cycle deployment of process technologies to achieve the path forward

a) Technology development - assures that optimal technologies are selected and developed efficiently

b) Technology implementation - assures the successful transfer and utilization of technology to day-to-day operations

c) Continuous process improvement - assures continual improvement in existing manufacturing processes

3) Support Infrastructure - assures that the proper type, quantity, and quality of infrastructure (physical and services) exists to support the successful completion of the path forward

Critical systems, because they produce customer value, invariably cross functional lines and involve people from many different departments. The Technology Deployment critical system, for example, has three subsystems and involves several functional departments - Operations, Technology Development, Projects, Strategic Planning, and Process Engineering. These three systems, if managed appropriately, will force the meaningful cross-functional communications oriented toward multi-department problem solving that are required to increase the level of innovation and adaptability within the Office and the Program. Explanations of the proposed critical systems and their subsystems and interrelationships are provided in Figures 2 and 3.

Figure 2 is a coarse graphical description of the INEEL High Level Waste System. It receives inputs from, and/or gives outputs to, the other Environmental Management (EM) programs at the site. On a site-wide basis, EM Programs has direct interfaces with other sites, state of Idaho, and the Navy. Complex-wide, EM Programs interfaces with other national organizations, such as the Nuclear Regulatory Commission (NRC), the Environmental Protection Agency (EPA), and the Waste Isolation Pilot Plant (WIPP). The inputs/outputs between the three subsystems of the INEEL HLW System are also shown in Figure 2. The Decision Making system is responsible for creating mechanisms to manage knowledge and to measure and control the coordination of decision making within the entire INEEL HLW System. To do this properly, Decision Making interfaces with the other two component systems to assure compatibility between its mechanisms and their needs, expectations, and constraints. The Support Infrastructure system provides facility- and communicationrelated support.

Figure 3 goes down one level of granularity to show internals of the Decision Making critical system. The diagram shows that the Organization and Culture subsystems provide outputs to the Knowledge Management and Coordination Control subsystems. The latter two subsystems interface with each other to provide the Decision Making outputs to the other critical systems. 


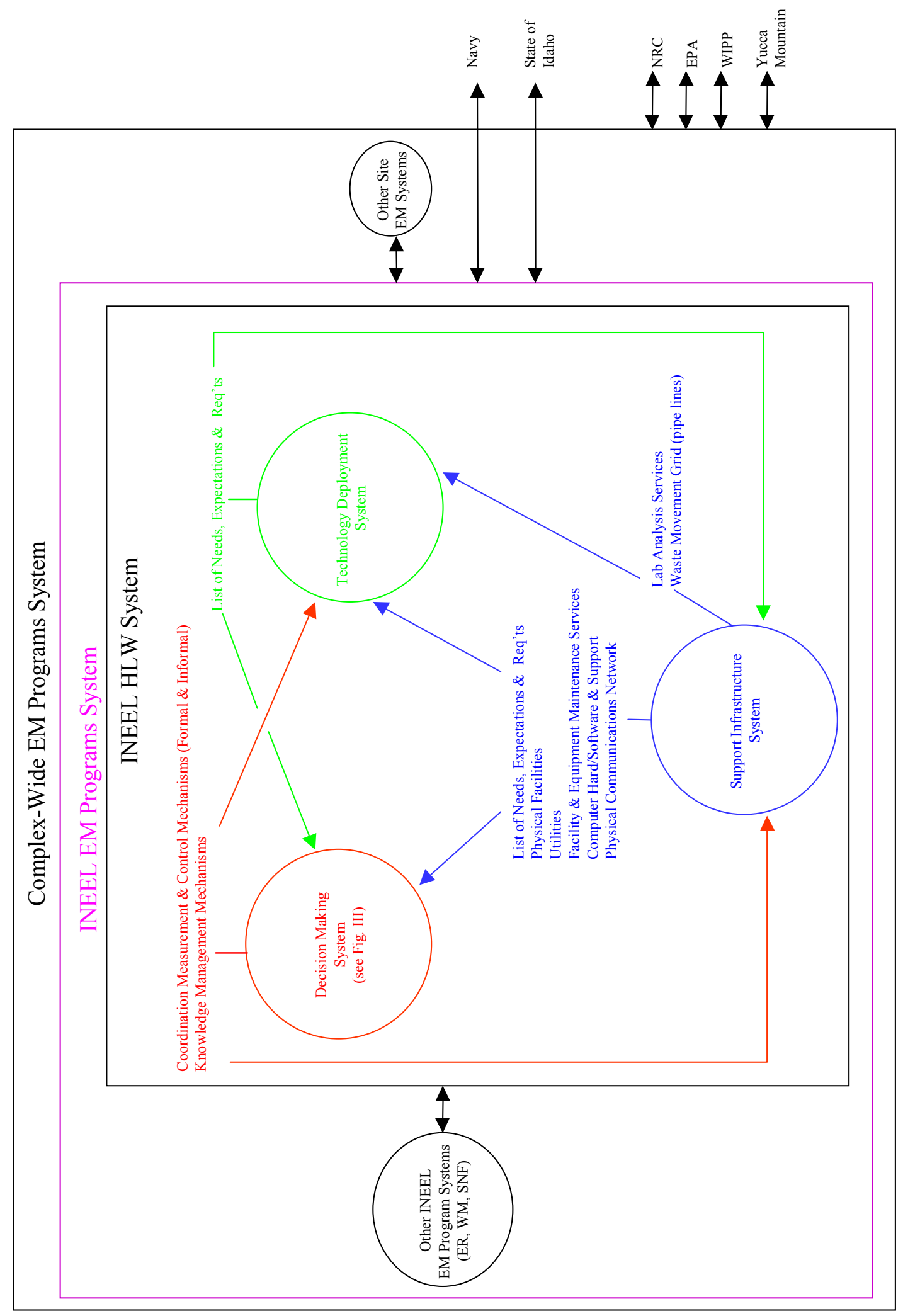

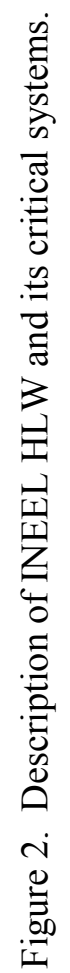




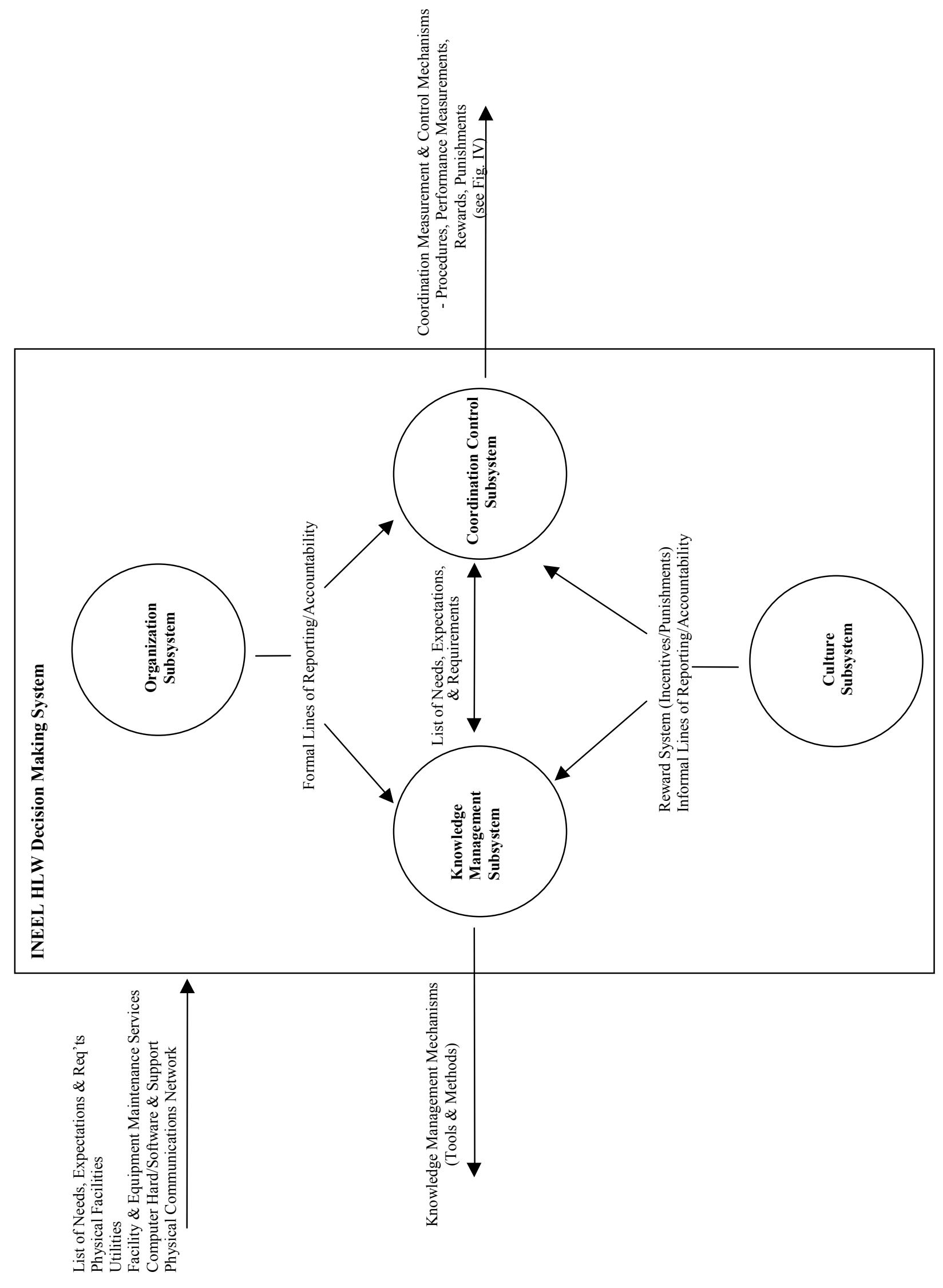

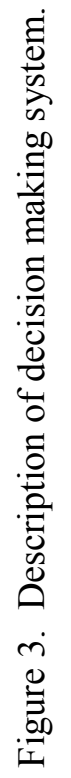




\section{Attend to, Coordinate, and Manage Critical Systems}

It is recommended that Kirby's (1991) six criteria for system ownership be strongly enforced when choosing system managers. For the time being, however, only a subpart - the HLW Program Office - feels strongly enough about the lack of cross-functional interfacing to take the lead in this behavioral change endeavor. Consequently, it is recommended that all initial managers of the critical systems be members (direct or matrixed) of the Program Office and that the Program Office implement the concept only within its own organization. The hope is that the other functional parts of the INEEL HLW System will gradually adopt the concept once they are involved in it via the interfacing efforts of the Program Office. Because the Decision Making system is the crux of the Program Office's endeavor to increase cross-functional problem solving, and its outputs are organizational structure, culture, and administrative policies, it is recommended that its owner be the Program Office manager. The Office manager satisfies all of the six ownership criteria within the Program Office, and it will give his staff the opportunity to see him "walk the talk" in a more active role. It is recommended that the Technology Development manager be the owner of the Integrated Technology Deployment critical system and that a member of the Office senior staff be assigned responsibility for Support Infrastructure.

\section{Emphasize Human Development}

Office management needs to assure that supervisors and managers of its functional sections have the necessary skills to both receptively listen and actively challenge in a constructive and teaching manner. Otherwise, subordinates will not learn the desired behaviors. Training may be required for some managers, and a few may even need to be removed from direct supervisory roles if they lack the desire to acquire the required skills.

\section{Tie Behavior, Measures, Objectives, and Customer Needs Together}

Parts of a performance measurement system for INEEL HLW are proposed as an explanatory strawman:

- Top Level End Result measures: period (such as monthly) cost and schedule variances; customer's performance evaluation scores

- Leading Indicator Behavior measures for Decision Making critical system: number of knowledge gaps identified and closed; number of new functional interfaces formally established

For most businesses, a revenue-related metric like total sales or market share can be an accurate end-result measure of customer satisfaction. The final products (development of a technology, or the disposal of a waste stockpile, for example) of the HLW Program are usually services aimed at mitigating negative situations that may take several years or decades to complete rather than a tangible product with life-enhancing features that can be purchased on demand at a retail shop. Consequently, DOE attempts to measure Program performance by assessing incremental progress over specified time intervals. Current practice is for DOE to give performance evaluation scores quarterly and annually.

As the capability valued by the customer is being created, INEEL HLW's estimates of schedule and cost should become more accurate and project execution smoother, resulting in decreasing cost and schedule variances. This should cause HLW's performance, as evaluated and scored by DOE, to increase. Trends in metrics are more important than absolute values. Monthly variances and quarterly customer performance evaluation scores would be plotted beginning with several years back and 
statistical changes in the measures would be sought to confirm or disprove correlation with the leadingindicator measures.

It is assumed that if members of INEEL HLW System are identifying knowledge gaps and uncertainties and resolving them in an effective manner that schedule/cost estimation will be more accurate, project execution smoother, and DOE more pleased. Consequently, gap identification and closure and interface development are considered to be leading-indicator measures of the end-result measures (the variances and customer performance evaluation scores). It is felt that improvement in the gap and interface measures can occur only if members of the INEEL HLW System become more engaged in cross-functional communications and problem solving.

The linkages between customer value added, desired employee behaviors, the example end-result measures, and the example leading-indicator performance measures of the proposed Decision Making Critical System are graphically displayed in Figure 4.

INEEL HLW management first has to assess what the customer values the most. Does DOE want an optimum implementation of the path forward? Is DOE more concerned about getting the entire job done than it is in marketing short-term results to the American public?

Assuming management is convinced the answers are "yes," management then needs to assess if cross-functional problem solving, with its emphasis on front-end effort to decrease back-end risks, is the behavioral leverage. Is the customer more concerned about life-cycle cost and schedule than the current year's budget? Given the short-term political cycles that can be caused by the country's 2- and 4-year terms of elected federal officials, is the long-term benefit from coordinated decision making considered worth the increase in front-end costs from DOE's perspective?

Again assuming the answers are "yes," management then creates critical systems to enable linkage between behavior and needs, leading-indicator measures to monitor real-time performance, and end-result measures to assess the gradual and delayed impact of the strategy. Each link shown in Figure 4 has to be confirmed repeatedly over time, so management has to be prepared to make adjustments as circumstances change and its knowledge of the customer and employee behavior increases. How much of the Program's cost/schedule variance at any point in time is due to a lack of integrated decision making, and how much is due to changing customer requirements? What is the impact of mid-stream changes in scope, budget, and/or schedule mandated by DOE? Will the customer reward better decision making with higher performance evaluation scores?

If the behavior change occurs, leading-indicator measures improve, and schedule/cost variances decrease but performance evaluation scores given by the customer remain statistically unchanged, there could be two explanations: 1) the targeted behavior is not contributing to the valued capability as much as management thought it would, or 2) the capability is being created but the customer, DOE, doesn't value it as much as management expected.

\section{Decouple Measurement from Evaluation}

It is important that all efforts of Office management to promote change are consistent with the message and content of the desired change (Richards and Engle, 1993). Since Office management's vision includes cross-functional problem solving, its own actions need to include such behavior. Management, for example, should change the focus of its monthly staff meetings to be more consistent with the desired behavior. Staff meetings reinforce to the troops what the manager considers important. Flow down administrative information from senior management can usually be distributed via e-mail. Consequently, it is recommended that each month an appropriate representative from another department be invited to come and discuss the needs and concerns of his/her functional organization. The main 


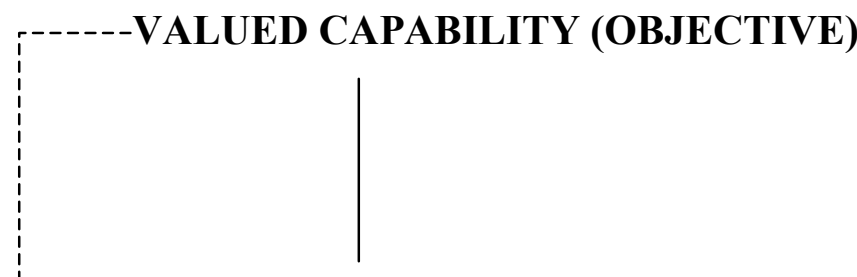

END-RESULT MEASURES

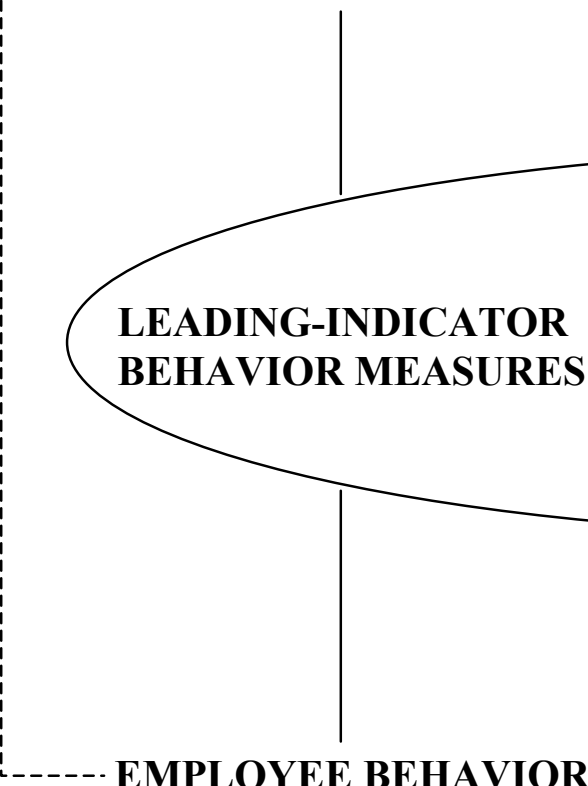

-Optimum implementation of path forward

-Customer's performance evaluation scores -Schedule/Cost variances

\section{Decision Making Critical System}

-Identification \& resolution of knowledge gaps -Interfacial development

-Cross-functional communication and problem solving -Systematic, integrated decision making

Figure 4. Tying Customer Needs To Employee Behavior. 
item on the meeting's agenda would be to discuss the interface and the concerns of the guest department, identifying gaps and problems. Assignments would be given to appropriate members of the Program Office's staff to work identified gaps and report next month with resolution action plans. This would result in the formal establishment of at least twelve cross-functional interfaces with corresponding action plans within the first year.

The MBO approach would suggest evaluating Program Office employees by narrowly-defined criteria, such as how many problems they identify or action plans they write. This would invite "gaming," however - employees would focus on minutia to increase the number of problems they "identified," for example. The behavior-based approach, on the other hand, suggests that employees be appraised on their contribution to the identification and resolution of cross-functional problems. Did the employee actively participate in a positive way in the exploratory staff meetings? Did the employee try to develop constructive relationships with identified interfaces? Did the employee willingly accept responsibility to work with an interface to resolve problems?

Some managers may need training to gain the increased managerial skill required for using subjective, broadly-defined criteria. A few may even need to be removed from direct supervisory roles if the required hands-on approach is not compatible with their personal managerial style.

\section{Emphasize Enterprise Alignment}

The fact that the employee behavior desired by the Program Office is not being exhibited to the desired degree is evidence that such behavior is currently neither evaluated nor rewarded enough by either the enterprise or Office management. Office management, therefore, has to first focus on achieving internal alignment.

Office management needs to make sure that its efforts to increase local innovation and adaptability do not significantly challenge the enterprise's bureaucracy. One possible strategy is to achieve the desired behavior change locally and hope outsiders will want to follow suit after they see the increased success the Office has, resulting in the gradual spreading of the new subculture through other parts of the enterprise over time. Such a strategy is recommended since a top-down mandate doesn't support the Program Office's desired change: create the behavior in Program Office personnel and hope that other interface organizations imitate the behavior once they see its benefits and success. Done in this way, potential negative effects of the cultural misalignment between the Office and enterprise can be minimized.

Once a desire for change is strong in other parts of the INEEL HLW System, it would be advantageous for Office management to discuss the systems approach with the other managers and modify the set of critical systems and rigorously apply the system manager criteria. This will transition the project from being driven by the Program Office to instead being driven by the higher-level INEEL HLW Program. The structure of critical systems will need to be dynamically modified and adjusted to account for new information continually obtained through internal and external interfacing and by extending the vantage point to higher levels and additional customer valued capabilities.

\section{Understanding, Congruency, and Commitment}

Staff meetings focused on interfacial development and managers measuring and rewarding the desired efforts and behaviors will help Office personnel to gain a clearer understanding of how they can contribute to the success of INEEL and DOE. Management discussing the possible reasons underlying the enterprise's bureaucracy will help Office employees to understand that their desires to contribute are aligned with those of most of the other INEEL and DOE employees who are also trying to deal with the 
enterprise's bureaucracy. This will help increase intrinsic satisfaction and commitment of Office employees to the local cultural change if Office management itself "walks the talk" by displaying strong integrative and communicative behaviors.

\section{Capturing, Sorting, and Sharing Knowledge}

Person-to-person (PTP) knowledge sharing is important to the HLW Program because of the large amount of tacit knowledge involved. But there are two factors impeding PTP sharing within the Program itself: scientists and engineers prefer working independently, and they view interfacing and coordination meetings as relatively unimportant managerial- or administrative-type tasks. The main thing Office management can do to counter act these tendencies has already been mentioned in the "Emphasize Human Development" section - evaluate and reward behaviors contributing to teamwork and knowledge capture, sorting, and sharing.

\section{Meeting Customer Needs (Ascending the Apex)}

A key to producing innovation and adaptability will be properly coordinating and managing the knowledge management system that was recommended as a subsystem of the proposed Decision Making critical system (see Fig. 3) because it produces the tools and mechanisms for capturing, sorting, and sharing knowledge.

Key to long-term success of the change effort will be a persistently high level of leadership attention, energy, and skill exerted by Office management over the long haul. Without such perseverance, commitment, and competency, the localized subculture created will not survive, nor will it have a chance of diffusing to the rest of the Program organization and beyond.

\section{Conclusions \& Recommendations}

Office management feels strongly that: 1) DOE highly values the capability to implement the HLW path forward within an optimum balance between schedule and cost that are accurately estimated beforehand; and 2) systematic decision making and cross-functional problem solving by HLW personnel are necessary behaviors to achieve such capability. The fact that the employee behavior desired by the Program Office is not being exhibited to the desired degree is evidence that such behavior is currently neither evaluated nor rewarded enough by Office management itself. Office management has to accept responsibility for its own contributing role to the current absence of the desired behaviors and realize its power to influence the behavior of if its own personnel. Office management, therefore, has to first focus on achieving internal alignment and increasing the level of integrative and communicative behaviors of its own personnel.

A set of critical systems, performance and evaluation measures, and tactics are proposed to help encourage the desired behaviors within the Office and help create the valued capability within the Program (see Figs. 2-4):

a) Performance Measurement

(1) Seeks to improve absolute value and decrease statistical variance

(2) End-Result Measures

(a) Period cost and schedule variances of INEEL HLW

(b) Performance evaluation scores of INEEL HLW Program by DOE 
b) Three critical, cross-functional systems

(1) Decision Making

(a) Owner/Manager - Program Office Manager

(b) Outputs

(i) Mechanisms to manage knowledge and to measure and control the coordination of decision making within the entire INEEL HLW System

(c) Subsystems

(i) Knowledge Management

(ii) Coordination Control

(iii) Culture

(iv) Organizational Structure

(d) Tactic

(i) Program Office consistently have monthly staff meetings focused on crossfunctional problem solving rather than administrative flow down

1. Invite representative from functional unit outside Program Office to discuss functional interdependencies

2. Assign appropriate Program Office personnel to report following month with action plan for formal interface establishment and knowledge gap resolution if needed

(e) Leading Indicator Measures (on a period basis)

(i) Quantity of knowledge gaps identified and closed

(ii) Quantity of new functional interfaces formally established

(2) Technology Deployment

(a) Owner/Manager - Technology Development Manager

(b) Outputs

(i) Needs, expectations, and requirements

(3) Support Infrastructure

(a) Owner/Manager - Program Office senior staff

(b) Outputs

(i) Facility- and communication-related services

c) Evaluation of Program Office employees

(1) Subjective - focused on behavior (means) rather than the measures (ends)

(a) Based on contribution to cross-functional problem solving

(i) Actively participate in a positive way in the exploratory staff meetings?

(ii) Trying to develop constructive relationships with identified interfaces?

(iii) Willingly accept responsibility to work with an interface to resolve problems?

The strawman presented here is deliberately incomplete because its purpose is explanatory. It is a starting point for further discussion and development within the Program organization. Inputs/outputs, tactics, and leading indicator measures need to be formulated for all the critical systems and their subsystems, and ties need to be made to the company's functional organization. The managers of the critical systems and subsystems, as owners, have responsibility for flushing out the details.

The Program Office, however, is also part of a larger bureaucratic enterprise that by nature is incongruent with the key behaviors identified by Office management. The conceptual model suggests that such localized behavior modification will be more difficult and time consuming because of the need to minimize this distant cultural misalignment. It is recommended that the Program Office start by applying the conceptual model and critical systems within its own organization to produce more integrated decision making internally. It is recommended that the main mechanism for spreading a desire for the key behaviors to the rest of the INEEL HLW Program and the site in the beginning be through inclusion into the proposed regular attempts to establish interfaces and solve cross-functional problems at Office staff meetings. This is one way to use behavior diffusion to help minimize enterprise misalignment. 
GE's CEO, Jack Welch, had a vision for his conglomerate that was based in part on globalization and the shared values of empowerment and autonomy of individual business units. The majority of business units were domestic players only. Although frustrating for Welch, he had to wait several years before the business units self-initiated their globalization efforts. Since the concept of shared values was a major part of his vision, he was forced to diminish his reliance upon coercive and reward powers. To have forced business units to adapt a globalization strategy would have been inconsistent with the vision (Tichy and Sherman 1994). Welch, similar to Richards and Engle (1993), felt that consistency was key.

It is recommended that Office management follows Welch's example and have its methodology be consistent with its vision. Systems thinking is essentially the behavior desired by Office management for decision making within the INEEL HLW Program, so Office management should exhibit systems thinking in its solution to the problem, i.e., implement a systems solution. This is a case where the objective and solution are one and the same. The objective of systematic, integrated decision making within the Program will eventually be achieved if Program management applies systems approaches, such as the one recommended in this proposal, to managerial problems. It is merely one form of "walking the talk."

This application of the conceptual model presented here is only an outline. Some steps may be combined, and some may be repeated or iterative. A different set of critical systems and owners could be chosen. The purpose of presenting an application strawman was to provide insight and guidance, not constraint. There is an old Japanese proverb that says, "Vision without action is a daydream." (Kotler 1997). The Program Office has a vision of the INEEL HLW Program performing in an integrated and systematic fashion. A high-level action plan to avoid that vision from becoming nothing more than a daydream has been proposed. 


\section{IMPLEMENTATION EXAMPLES}

There is one basic recommendation with respect to implementing the proposal, and that is to let subordinates and lower-level employees find a solution to the problem. Office management should supply the general idea and managerial support, but subordinates should make the rest of the decisions. When John Trani, the head of GE's Medical Systems business unit, decided that globalization was required for long-term profitability, he was concerned because of the lack of communication between his unit's executives in different countries. The American, French, and Japanese are considered to be among the most arrogant national cultures, and some of his executives from those countries weren't even on speaking terms with each other. It is easy to lose the awareness of the whole enterprise in the tangle of functional, product, and national rivalries.

Trani became convinced that process-based systems that crossed national boundaries were the key to overcoming these integration barriers. He acted on that conviction by forming teams composed of his executives to determine what process-based organization would be the best. The result of the teams' efforts was the recommendation for an organization based on six processes. Trani then assigned teams to develop the detials of each of the individual process systems. Once that was done, he and his leadership teams then focused on implementation plans.

During implementation, the leadership team decided that it would be best to pull back somewhat and limit the initial scope of the change effort to only two systems that were expected to have the greatest impact. Trani provided the general solution of process-based systems and his full support. However, his subordinates, who had more detailed knowledge of the guts of the problem, defined the scope, determined what systems would actually be created, developed the implementation plans, and coordinated the change efforts' execution. This instilled ownership for the change in his subordinates and eased its implementation (Tichy and Sherman 1994).

In a different company, a division head was frustrated with the lack of communication between his functional departments and felt that cross-functional teams were the answer (Beer, Eisenstat, and Spencer, 1990). He felt strongly that behavior isn't changed by changing formal structure but rather by changing roles, responsibilities, and relationships. Changes in these three "r"s force people to change their behavior.

The leader formed a 20-person group representing all organizational stakeholders to discuss the issues. He shared his vision of task-alignment with the group, and the group members agreed with the general concept of aligning roles and responsibilities around critical tasks rather than functions. He and the group developed a shared diagnosis of what was wrong and how to resolve it. The group identified all the tasks needed to be competitive and came up with a system of cross-functional teams to accomplish the tasks. These teams were to be ad hoc; that is, they would overlay rather than replace the existing, formal, functional organization. This activity resulted in a core group being committed to a particular analysis of the problem.

The leader followed this activity by creating a larger 90-person task force to refine the team model and fill in the details. His aim was to extend the consensus and commitment to a broader base of employees. This task force then presented its findings to the entire work force. The leader supported the findings of each of the task forces. When the change plans were formally announced to the entire work force, the leader leveraged coercive and reward powers by making it clear that the plans of the task forces would be implemented - outplacement and counseling were offered to those not wanting to help in the endeavor.

The situation of both of these examples is similar to that of the INEEL HLW Program Office. Leaders realized their organization's competitiveness was weakened by a lack of complete focus on the 
customer, and they realized that the lack had its roots in employee behavior. Both leaders felt that crossbarrier (national, geographical, or functional) teams focused on critical processes or tasks were the key to causing a change in behavior.

Being in a similar situation, it is recommend that Program Office management adopt the same implementation approach that these two leaders did: they presented their perceived behavior-based problem and general solution of a system of cross-functional teams to subordinates, sought their feedback and consensus, empowered them to make all the rest of the decisions, and gave them the required support.

\section{Conclusions}

The implementation of the critical systems concept differed in these two examples. One appears to have involved formal-based team or committee structure, while the other had ad hoc teams. Formal or informal is not the important characteristic. What is important is that the relationships, responsibilities, and roles of the participants were changed to be aligned in such a way that they forced and nourished meaningful cross-functional communications and problem solving.

The leaders discussed in these two examples did not abdicate their responsibility to lead; on the contrary, they were actively involved by providing the vision and general concepts, requesting open and honest feedback, delegating, challenging, supporting, and following-up.

There are two major differences, however, between these two examples and the INEEL HLW Program. First, the former were relatively independent and autonomous units, whereas the later is not. The later has to worry about alignment with the rest of the enterprise much more than in the two examples. Second, transformational change occurred in the examples, but only transitional change is sought at this time by the INEEL HLW Program Office. Consequently, the scope and schedule baselines for the INEEL HLW Program change effort will be more constrained than in the examples. 


\section{REFERENCES}

Anthony, Robert N. and Vijay Govindarajan, 1998, Management Control Systems, 9th Edition, San Francisco: Irwin McGraw-Hill, Chapters 3, 11, and 15.

Beer, Michael, Russell A. Eisenstat, and Bert Spencer, 1990, "Why Change Programs Don't Produce Change," in Managing Change: Cases and Concepts by Todd D. Jick, 1993, San Francisco, California: Irwin McGraw Hill, pp. 264-276. Originally printed in Harvard Business Review, November-December 1990, pp. 158-166.

Bounds, Gregory M., James M. Reeve, and Kenneth C. Gilbert, 1991, "Managerial Performance Measurement," Competing Globally Through Customer Value: The Management of Strategic Suprasystems, Edited by Michael J. Stahl and Gregory M. Bounds, New York: Quorum Books, Chapter 16.

Galagan, Patricia, 1997, "Smart Companies," Training \& Development, Vol. 51, No. 12, December, pp. 20-24.

Hansen, Morten T., Nitin Nohria, and Thomas Tierney, 1999, "What's Your Strategy For Managing Knowledge?," Harvard Business Review, March-April, pp. 106-116.

Hawkins, Peter, 1997, "Strategies for Cultural Change," Human Relations, Vol. 50, No. 4, December, pp. 417-440.

Jick, Todd D., 1993, Managing Change: Cases and Concepts, San Francisco, California: Irwin McGraw Hill, pp. 1-8.

Kornacki, Mary Jane and Jack Silversin, 1998, "How can IDSs integrate conflicting cultures?," Healthcare Financial Management, Vol. 52, No. 6, June, pp. 34-36.

Kirby, Kenneth E., 1991, “Organizational Change: The Systems Approach,” Competing Globally Through Customer Value: The Management of Strategic Suprasystems, Edited by Michael J. Stahl and Gregory M. Bounds, New York: Quorum Books, Chapter 11.

Kotler, Philip, 1997, Marketing Management: Analysis, Planning, Implementation, and Control, 9th Edition, New Jersey: Prentice Hall, Chapter 1 \& pg. 744.

Martin, James N., 1997, Systems Engineering Guidebook, New York: CRC Press, Preface/Chapter 1/Appendix A.

Morgan, Charles D., 1998, "Culture Change/Culture Shock," Management Review, Vol. 87, No. 10, November, pg. 13.

Pascale, Richard, Mark Millemann, and Linda Gioja, 1997, "Changing The Way We Change," Harvard Business Review, November-December, pp. 127-139.

Richards, Dick and Sara Engle, 1993, "After The Vision: Suggestions To Corporate Visionaries And Vision Champions," in Managing Change: Cases and Concepts by Todd D. Jick, 1993, San Francisco, California: Irwin McGraw Hill, pp. 83-97. Originally printed in Transforming Leadership, John D. Adams, General Editor. 
Saunier, Anne and Mary Mavis, 1998, "Fixing a Broken System," HR Focus, Vol. 75, No. 3, March, pp. $1-3$.

Senge, Peter M., 1990, The Fifth Discipline, New York: Doubleday Currency.

Simons, Robert, 1995, Levers of Control: How Managers Use Innovative Control Systems to Drive Strategic Renewal, Boston: Harvard Business School Press, Chapter 5.

Strebel, Paul, 1996, “Why Do Employees Resist Change?," Harvard Business Review, May-June, pp. 8692.

Tichy, Noel M. and Stratford Sherman, 1994, Control Your Destiny or Someone Else Will, Harper Business, Chs. 2, 15, and 17.

Vaas, Lisa, 1991, “Brainstorming,” PC Week, May 31, pp. 65-68. 